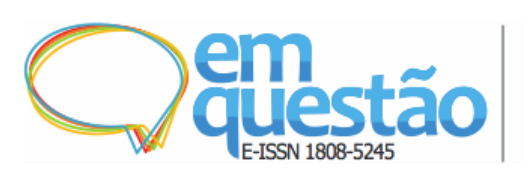

\title{
(Des) Informação e [Pós] Verdade: possíveis contextos discursivo-conceituais
}

\author{
Vera Dodebei \\ Doutora em Comunicação e Cultura; Universidade Federal do Estado do Rio de Janeiro; Rio de Janeiro; \\ RJ; Brasil \\ dodebei@gmail.com
}

\begin{abstract}
Resumo: Este artigo tem por objetivo discutir as ideias de desinformação e pósverdade a partir de seus opostos - informação e verdade. À luz da teoria do conceito em Dahlberg, complementada por análise de três narrativas fílmicas, foram descritos possíveis cenários conceituais com o apoio de busca bibliográfica ultra seletiva sobre cada um dos conceitos. Robert Logan conduziu a discussão sobre o conceito de informação e Nicola Abbagnano sobre o de verdade. Vladimir Volkoff historiografou o conceito de desinformação e o Oxford Languages, o de pós-verdade. Como conclusão, os atributos verdadeiros ou características conceituais garantidas pela literatura permitiram afirmar a circunstancialidade dos contextos culturais em que esses conceitos se organizam, bem como possibilitaram apresentar duas estruturas de análise: uma discursiva e polissêmica (narrativas fílmicas) e outra conceitual e redutora semântica (mapa conceitual) para as ideias de informação e desinformação, verdade e pós-verdade.
\end{abstract}

Palavras-chave: Desinformação. Informação. Pós-Verdade. Verdade. Teoria do conceito.

\section{Introdução}

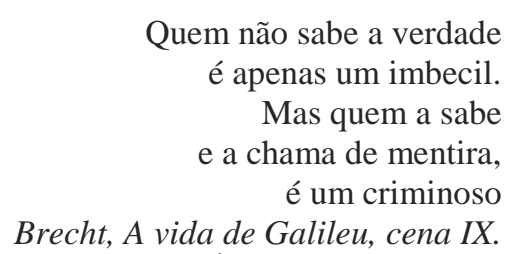

(RÓNAI, 1985, p. 976).

Este artigo se propõe a levantar questões sobre os conceitos de desinformação e de pós-verdade, mais do que perseguir a tentativa de explicitá-los. Fruto de uma conferência proferida em agosto de 2019, o artigo (que a amplia) traz ao leitor um pouco das histórias dos dois conceitos, o nascimento das ideias e seus efeitos 
benéficos e perversos para a sociedade sob o olhar de seus opostos - Informação e Verdade.

Informação e Verdade são construções teóricas polissêmicas, subjetivas e circunstanciais. Junta-se a esses conceitos, as ideias de desinformação e pósverdade. Talvez seja interessante analisar, como introdução a essa questão, o discurso de Robert Logan. Em seu livro Que é informação? Logan (2012) destaca a importância da informação e seu papel preponderante na sociedade contemporânea com foco no século XXI. Ao contrário de outros teóricos que tentam explicitar o que a informação é em seu aspeto histórico, Logan (2012) abre mão da hierarquização temporal, em prol de uma análise dos contextos em que a informação estabelece laços laterais com as culturas. O autor realiza essa verificação a partir de Shannon (1975) e de sua teoria matemática da comunicação que gerou a teoria da informação.

Ao demonstrar que "a informação não é uma invariante, posto que sua definição depende do contexto no qual está sendo usada", Logan (2012, p. 253) levanta e responde às questões colocadas do início de seu texto:

[...] qual é a relação da informação com o significado, com a comunicação e com a organização?; informação é uma coisa, como um substantivo, ou um processo, como um verbo?; a informação é material, uma forma de energia ou é apenas um padrão?; a informação é um fenômeno exclusivamente humano ou as formas não humanas de vida contém informação também?; qual o papel da informação na propagação da vida?; qual é a relação da informação com a energia e a entropia?; qual a relação da informação com a ciência?; qual a relação da informação com a mídia?; a informação e o seu processamento desempenham um papel nas artes? (LOGAN, 2012, p. 253-255).

Em uma síntese de suas respostas, é possível concluir que a informação, para Logan (2012) depende da cultura e de suas subunidades: linguagem, tecnologia, ciência, economia e política, que são organismos vivos ou organismos biológicos. Diante disso, a informação é mais que um substantivo: ela é um processo. Sobre sua materialidade, essa condição dependerá do contexto de observação. Por exemplo, a informação contida no DeoxyriboNucleic Acid (DNA) é material mas, para o pensamento humano, a informação é simbólica. Sobre a Verdade, é relevante verificar em um dicionário filosófico como 
o verbete é apreendido por seu autor e, no caso, o escolhido foi Nicola Abbagnano (2000). Talvez pelo senso comum e, a partir do que concluiu Logan (2012) sobre a ideia de Informação, é possível compreender que o significado de Verdade vai depender do contexto em que a ideia está disposta. Por exemplo: se a interrogação parte da crença religiosa ocidental e de seus dogmas, verdade é o verbo, é Deus.

No caso em que se busca o caminho da ciência, a verdade é sempre circunstancial, mesmo que comprovada a partir de evidências. Ainda, ao trilhar os caminhos do conhecimento tradicional indígena ou dos povos da floresta, a dificuldade em definir e categorizar tais experiências cognoscitivas é ampliada pois, sabiamente, esses povos não encontram relações de oposição entre esses modos de conhecer, apenas modos circunstanciais de reconhecer.

Como exemplo dessa circunstancialidade, o livro A queda do céu: palavras de um xamã yanomami, de David Kopenawa e Bruce Albert (2015) propõe (aos não índios) um novo modo de ler o mundo e a natureza, incluindo nela os seres humanos e não humanos. Do mesmo modo, o ambientalista Ailton Krenak, em matéria de William Helal Filho publicada em O Globo, diz que "[...] é preciso entender a floresta como um mundo repleto de humanidades, e não um arranjo de árvores ou fonte de recursos" (KRENAK, 2019, p. 28). Para Krenak (2019), a sociedade está imersa numa ecologia do desastre já denunciada por Kopenawa e Albert (2015) em A queda do céu.

\footnotetext{
Não são apenas os índios, mas também os brancos, que estão ameaçados pela cobiça de ouro e pelas epidemias introduzidas por estes últimos. Todos serão arrastados pela mesma catástrofe, a não ser que se compreenda que o respeito pelo outro é a condição de sobrevivência de cada um. [...] É emblemático que caiba a um dos últimos porta-vozes de uma sociedade em vias de extinção, como tanto outras, por nossa causa, enunciar os princípios de uma sabedoria da qual também depende - e somos muito poucos a compreendê-lo nossa própria sobrevivência. ( ${ }^{1}$ LÉVI-STRAUSS, 1993, p. 7 apud KOPENAWA; ALBERT, 2015, p. 5).
}

Em Abbagnano (2000), o termo Verdade significa a validade ou eficácia dos procedimentos cognoscitivos.

Em geral, entende-se por V. a qualidade em virtude da qual um procedimento cognoscitivo qualquer torna-se eficaz ou produz êxito. Essa caracterização pode ser aplicada tanto às concepções segundo as quais o conhecimento é um processo mental quanto ás que o 


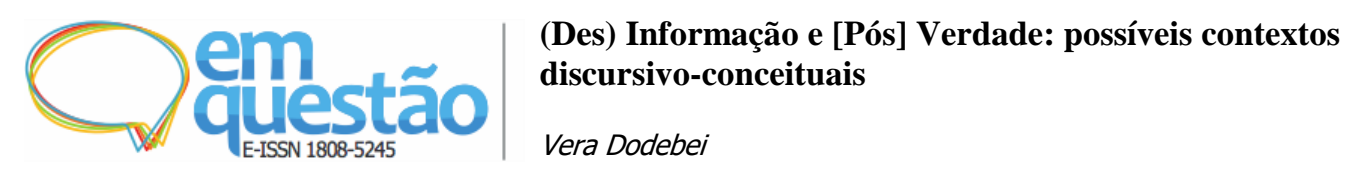

consideram um processo linguístico ou semiótico. (ABBAGNANO, 2000, p. 994)

No entanto, mais do que polissêmico, este conceito é apropriado, de maneira geral, por filósofos que o definem segundo as apreensões de mundos que constroem como, por exemplo, as ideias de: correspondência entre o conhecimento e a coisa; revelação; conformidade a uma regra; coerência; e utilidade. Essa densa discussão filosófica foi sintetizada em uma matriz que organiza os filósofos, as categorias e as definições conceituais, a que denominamos de mapa descritivo do verbete Verdade: 
Vera Dodebei

Quadro 1 - Mapa descritivo do verbete Verdade

\begin{tabular}{|c|c|}
\hline \multicolumn{2}{|r|}{1 - CONCEITO DE VERDADE POR CORRESPONDÊNCIA } \\
\hline $\begin{array}{l}\text { Estoicos } \\
\text { e Epicuristas }\end{array}$ & $\begin{array}{l}\text { Verdade é a correspondência entre o conhecimento e a coisa. (mani- } \\
\text { festação do objeto para o homem) }\end{array}$ \\
\hline Platão & $\begin{array}{l}\text { Verdadeiro é o discurso que diz as coisas como são; falso é o que diz } \\
\text { como não são. }\end{array}$ \\
\hline Aristóteles & $\begin{array}{l}\text { Negar aquilo que é e afirmar aquilo que não é, é falso, enquanto } \\
\text { afirmar o que é e negar o que não é, é a verdade. }\end{array}$ \\
\hline Kant & $\begin{array}{l}\text { Verdade como acordo do conhecimento com seu objeto (conformi- } \\
\text { dade do conhecimento com suas regras) }\end{array}$ \\
\hline \multicolumn{2}{|c|}{2 - CONCEITO DE VERDADE POR REVELAÇÃO OU MANIFESTAÇÃO } \\
\hline S. Agostinho & $\begin{array}{l}\text { Deve existir uma natureza que esteja tão próxima da unidade que } \\
\text { a reproduz em tudo e é una com ela; essa natureza é a verdade, ou } \\
\text { verbo, Deus. }\end{array}$ \\
\hline Descartes & $\begin{array}{l}\text { Verdades eternas são tudo o que se manifesta de modo exigente } \\
\text { (cogito) }\end{array}$ \\
\hline Hegel & $\begin{array}{l}\text { A ideia (Verdade) é a objetividade do conceito, a racionalidade do } \\
\text { real, mas à medida que se manifesta à consciência na sua necessi- } \\
\text { dade, ou seja, como saber ou ciência. }\end{array}$ \\
\hline Husserl & $\begin{array}{l}\text { Verdade e evidência pertencem não só aos objetos teóricos, mas a to- } \\
\text { dos os objetos da consideração fenomenológica, sejam eles valores, } \\
\text { sentimentos etc. }\end{array}$ \\
\hline Heidegger & $\begin{array}{l}\text { Nexo estreito entre o modo de ser da verdade e o modo de ser do } \\
\text { ser humano, ou ser-aí, porquanto só ao ser humano a Verdade pode } \\
\text { revelar-se e revela-se. }\end{array}$ \\
\hline \multicolumn{2}{|r|}{ 3- CONCEITO DE VERDADE COMO COERÊNCIA } \\
\hline Bradley & $\begin{array}{l}\text { Os graus de Verdade que o pensamento humano alcança podem ser } \\
\text { julgados e classificados segundo o grau de coerência que possuam, } \\
\text { embora essa coerência seja sempre aproximativa e imperfeita } \\
\text { (terceiro gênero de conhecimento - Spinoza) }\end{array}$ \\
\hline \multicolumn{2}{|r|}{4 - CONCEITO DE VERDADE COMO UTILIDADE } \\
\hline Nietzsche & $\begin{array}{l}\text { Verdadeiro em geral significa apenas o que é apropriado à } \\
\text { conservação da humanidade. O que me faz perecer quando lhe dou } \\
\text { fé não é verdade para mim; é uma relação arbitrária e ilegítima do } \\
\text { meu ser com as coisas externas. }\end{array}$ \\
\hline
\end{tabular}

Fonte: Elaborado pela autora (2020). 
Pode-se acreditar em micróbios? O mapa descritivo ressalta que o conceito de verdade além de polifônico dentro de uma mesma área - a Filosofia -pode ser compreendido como Ciência, como Dogma e como Conhecimento Tradicional. A existência de micróbios é provada pela experiência científica e não vem da crença dogmática. Assim como o formato da terra vem também da observação científica, a afirmação por crença que ela é plana não precisa de verificação ou comprovação.

Na classificação de Abbagnano (2000), Nietzsche foi o que mais se aproximou dos conhecimentos tradicionais quando diz que verdadeiro, em geral, significa apenas o que é apropriado à conservação da humanidade. Nesse sentido, verdade passa a ser um constructo social, longe de alcançar o consenso. Talvez, essa organização de ideias representada no mapa descritivo (Quadro 1) possa ajudar a compreender o sucesso (para o bem e para o mal) das notícias falsas nas redes sociais, principalmente no campo da política. Parece não haver interesse por parte de alguns segmentos da sociedade em comprovar a veracidade de uma notícia, desde que se creia nela. A crença sobre a existência de um objeto, dispensa a prova ou a ignora. A dúvida, característica da ciência, e uma nova leitura de mundo em direção à 'solidariedade', como proposto por Kopenawa e Albert (2015) e Krenak (2019), quiçá possam ajudar a ver por entre a neblina da ignorância.

\section{Metodologia}

Para falar sobre "desinformação" e "pós-verdade" foi escolhida uma trama conceitual que abriga contextos sócio-históricos-memoriais e filosóficoinformacionais. Além disso, tentou-se encontrar, na literatura, discursos que pudessem elucidar os inúmeros sentidos, no espaço e no tempo, para as duas expressões.

A primeira etapa foi efetuar uma busca bibliográfica ultra seletiva sobre cada um dos conceitos. Ultra seletiva significa a escolha de uma única referência bibliográfica para discutir cada conceito. Robert Logan conduziu a discussão sobre o conceito de informação e Nicola Abbagnano sobre o conceito de verdade. 
Vladimir Volkoff historiografou o conceito de desinformação e o Oxford Dictionaries o conceito de pós-verdade.

Em seguida, foram identificados seus atributos verdadeiros garantidos pela literatura, de modo a criar um universo conceitual que permitiu enxergar as principais relações de contextos culturais que pudessem abrigar as ideias de informação e desinformação e de verdade e pós-verdade.

Procurou-se, também, aprofundar os estudos sobre a literatura que aborda as relações entre os objetos - informação e verdade - e sua possível desconstrução conceitual, relação contraditória ou de oposição. Em Dahlberg $(1992,1978)$ foi encontrada uma proposta para mapear esse campo complexo, à luz da teoria do conceito. A autora indica que, em função de seu conteúdo ou significado, as relações entre os conceitos se dão mediante comparações: lógicas, formais, abstratas ou semânticas, incluindo a contradição e o contrário.

Por fim, para discutir o contexto com mais propriedade procurou-se identificar, como campo empírico, três narrativas fílmicas objeto de análises que foram denominadas memo-informacionais, com enredos sobre narrativas falsas e narrativas ficcionais. As análises memo-informacionais são realizadas a partir do confronto entre teorias da memória e teorias da informação e suas possíveis relações com as narrativas no campo empírico (senso/dissenso).

\section{Desinformação}

Para a primeira questão sobre o que é desinformação, encontramos algumas respostas em Vladimir Volkoff(1999) na sua - Petite histoire de la désinformation e na Intervozes - Coletivo Brasil de Comunicação Social -, que elaborou uma “cartilha sobre desinformação" (INTERVOZES, 2019). Falaremos primeiro sobre a obra de Volkoff por ser seu discurso pautado na história do conceito de desinformação, já que a cartilha, de certo modo, estabelece diálogo e está representada genericamente no mapa conceitual sobre desinformação (BRISOLA; DOYLE, 2019), apresentado mais adiante.

Vale ressaltar a importância da obra obrigatória nos estudos de Ciências da Informação e Comunicação na França no final do século passado. O livro é a 
Petite histoire de la désinformation: du cheval de Troie à Internet, de Vladimir Volkoff (1999).

Vladimir Volkoff é um francês de origem russa que escrevia romances e novelas de espionagem. Se interessava pelos temas da Guerra Fria, espionagem, inteligência e manipulação. Bisneto do compositor Tchaikovsky, estudou na Sorbonne e foi oficial da inteligência francesa na guerra da Argélia, onde aprendeu que na guerra se luta tanto nas sombras e nas embaixadas quanto nos campos de batalha propriamente ditos. Ele popularizou o termo "desinformação" na França, ao escrever uma série de livros sobre o tema.

Para Volkoff (1999), um fato não é uma informação. Um fato só vira uma informação quando um informante informa um informado. O autor fala da diferença que fazem os militares entre informação (em estado bruto) e informe (informação bruta passada por uma tripla peneira: avaliação da fonte, avaliação da informação e confirmação da informação). Segundo Volkoff (1999), se uma pessoa diz - Chove - isto só é uma informação quando ela, por exemplo, telefona para comunicar o fato. Em outro exemplo, pela disciplina militar, quando alguém é avaliado, se nunca mentiu, é uma fonte confiável. E, ainda, se a estação do ano é março, então a probabilidade de chover é grande, ou seja, a informação deve proceder. Por fim, se meu vizinho também disse que está chovendo, sua fala confirma a informação.

Volkoff (1999) passa então para três premissas fundamentais para se discutir a desinformação: uma informação nunca representa $100 \%$ da verdade (não existe omnisciência); não existe objetividade (qualquer pretensão à neutralidade é suspeita); é natural que cada testemunha tenha sua própria visão do evento do qual participou (o contrário é suspeito).

Segundo Volkoff (1999), logo depois da II Guerra Mundial, a palavra desinformação aparece pela primeira vez em russo (dezinformatsiya) para fazer referência a práticas exclusivamente capitalistas com vistas a submeter as massas populares. $\mathrm{O}$ autor entende que, quando os soviéticos atribuem uma prática a adversários que ainda não a tinham descoberto, a palavra já se presta ao seu significado. 
Volkoff (1999) vê a desinformação tanto como um conjunto de técnicas quanto como uma filosofia, e dá, ao longo de seu livro, muitos exemplos de campanhas de desinformação (mal ou bem-sucedidas). Para propor uma definição de desinformação, o autor procede, como muitas vezes em casos de conceitos escorregadios, por contraposição ao que ela não é. Assim, Volkoff (1999) define Propaganda (sem meios deturpados), Publicidade (sem fins políticos) e Intoxicação (sem manipulação da opinião pública), para então propor que a desinformação é uma manipulação da opinião pública, para atingir a fins políticos, com uma informação tratada por meios deturpados.

O autor pondera que a desinformação não é sempre uma campanha profissional produzida estrategicamente com uma finalidade específica (VOLKOFF, 1999). "Ela é frequentemente o testemunho de um estado de espírito coletivo [...]" (VOLKOFF, 1999, p. 163) que pode ser percebido em acessórios aparentemente neutros como manuais escolares, dicionários e gramáticas. Volkoff (1999) dá o exemplo de como a escolha das ilustrações no Petit Robert des noms propres (dicionário de nomes próprios muito conhecido e utilizado na França) indica, na sua visão, um projeto esquerdista da intelectualidade francesa.

Volkoff (1999) encerra sua pequena história da desinformação com pessimismo, entendendo que a situação é muito ruim, mas aponta algumas soluções para profissionais/jornalistas e Estado, cada um com seus níveis de responsabilidade e limites para ação.

\section{Pós-Verdade}

A segunda questão - O que é Pós-Verdade? - nos levou ao Oxford Languages ([2016]), que elegeu o termo Pós-Verdade como a palavra-chave do ano de 2016. Após muita discussão, debate e pesquisa, o dicionário inglês descreve o conceito Pós-Verdade como "[...] um adjetivo definido relativo a, ou que denota circunstâncias em que fatos objetivos são menos influentes na formação da opinião pública do que o apelo à emoção e à crença pessoal." (OXFORD LANGUAGES, [2016]). 
O verbete escrito por um comentarista cultural convidado, Neil Midgley, considera que o conceito de pós-verdade existe desde a década passada, mas o Oxford Dictionaries viu um pico de frequência do termo no ano de 2016 (Figura 1), no contexto do referendo sobre a União Européia (Brexit) no Reino Unido e da eleição presidencial nos Estados Unidos.

Pós-verdade também foi associado a um substantivo em particular, na expressão 'pós-verdade política'. A pós-verdade deixou de ser um termo periférico para se tornar um dos pilares dos comentários políticos, sendo agora muitas vezes usado por grandes publicações sem a necessidade de esclarecimento ou definição em suas manchetes.

Figura 1 - Uso da expressão Pós-Verdade

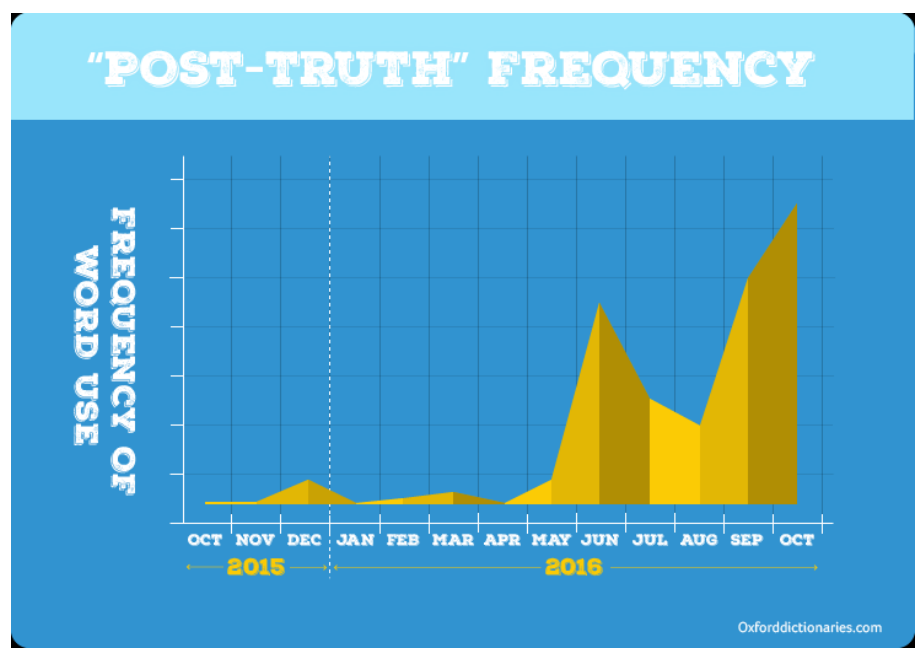

Fonte: Oxford Languages ([2019?]).

Independentemente à questão tecnológica, segundo ainda o Oxford Languages ([2016]), a expressão pós-verdade exemplifica uma expansão no significado do prefixo pós - que se tornou cada vez mais proeminente nos últimos anos. Em vez de simplesmente referir-se ao tempo após uma situação ou evento especificado - como no pós-guerra ou pós-correspondência - o prefixo em pósverdade tem um significado como pertencer a um tempo em que o conceito verdade - tornou-se sem importância ou irrelevante.

Essa nuança parece ter se originado em meados do século $\mathrm{XX}$, em formações pós-nacionais e pós-raciais. A pós-verdade parece ter sido usada pela 
primeira vez nesse sentido em um ensaio de 1992, do falecido dramaturgo Steve Tesich (The Nation Magazine). Refletindo sobre o Irã e a Guerra do Golfo Pérsico, Tesich lamentou que "[...] nós, como povo livre, decidimos livremente que queremos viver em algum mundo pós-verdade" (OXFORD LANGUAGES, [2016]).

Ainda segundo o Oxford Dictionaries (OXFORD LANGUAGES, [2016]), há evidências da expressão pós-verdade sendo usada antes do artigo de Tesich, mas aparentemente com o significado transparente depois que a verdade era conhecida, e não com a nova implicação de que a própria verdade se tornou irrelevante.

O livro The Post-truth Era, de Ralph Keyes foi lançado em 2004 e, um ano após o comediante norte-americano Stephen Colbert popularizou uma palavra informal relacionada ao mesmo conceito: veracidade, definida por Oxford Dictionaries como "[...] a qualidade de parecer ou ser verdade, mesmo que não seja necessariamente verdade" (OXFORD LANGUAGES, [2016]). A pósverdade estende essa noção de uma qualidade isolada de afirmações particulares a uma característica de nossa época.

A pós-verdade, considerando a história do conceito, os sentidos analisados pelo Oxford Languages ([2016]) e a ideia de construção de verdades individuais a partir das mídias digitais, leva ao que Byung-Chul Han (2013) considera mídia de presença. Diz o autor de No enxame que

A comunicação digital se caracteriza pelo fato de que informações são produzidas, enviadas e recebidas sem mediação. Elas não são mediadas e filtradas, e a instância interventora é cada vez mais dissolvida". (HAN, 2013, p. 35).

Tem-se a impressão que o protagonismo não vem mais da notícia do jornal, da revista semanal, mas do internauta que é o produtor da informação. Essa é falsa ou verdadeira? A minha verdade é a única que conta? Han (2013) diz ainda que a pressão da 'desmediatização' se estende à política e ameaça a democracia representativa. Por exemplo, os dados do desmatamento da Amazônia devem passar pelo presidente brasileiro antes da divulgação global por questões de zelo com o tratamento e suas consequências políticas? Isso indicaria uma 
responsabilidade, uma resistência governamental à tendência de uma informação desmetiatizada. Por outro lado, a propaganda eleitoral mobilizada durante o pleito fez o gesto oposto, quando priorizou as mídias digitais, fomentando a criação de verdades individuais isoladas, não publicizadas e, assim, livres de crítica.

\section{Representação de cenários para a ideia de desinformação}

Duas experiências serão apresentadas, as quais servem para ilustrar, de um lado, as narrativas fílmicas e, de outro, um mapa conceitual que propõe uma síntese de representação dos conceitos de pós-verdade e desinformação. Trata-se então, não de um embate ao gosto de Walter Benjamin (1994) entre narrativa e informação ou como explicita Dodebei (2016) em Ensaio sobre memória e informação, mas apenas de construção de cenários possíveis.

\subsection{Análises fílmicas}

Três filmes já analisados no âmbito da pesquisa Informação, memória $e$ documento ilustram as relações entre Desinformação/Pós-verdade e Informação (Wag the $d o g /$ Mera coincidência); Desinformação/Pós-verdade e Memória ( $L a$ dame de chambre du Titanic/A camareira do Titanic) e Desinformação/Pósverdade e História (Joe Gould's secret/Crônicas de uma certa Nova York).

O primeiro, Mera Coincidência (no original, Wag the dog), dirigido por Barry Levinson em 1997, descreve a história de um Presidente norte-americano que, a duas semanas da reeleição, se vê frente a uma denúncia (MERA..., 1997). Trata-se de seu envolvimento em um escândalo sexual com uma estudante em visita à Casa Branca, que será divulgado na mídia pela propaganda eleitoral de seu principal oponente.

A assessora da presidência, atendendo as instruções do próprio Presidente que se encontra afastado do país, manda buscar um profissional de marketing político para sustar a onda de difamação do candidato à presidência e líder nas pesquisas de intenção de votos. 
Ao propor criar 'um fato novo', o marqueteiro sugere iniciar uma 'guerra contra a Albânia'. Surgem então as questões: manipular fatos que podem ter repercussões para o futuro é informar? Quem avalia o estatuto de verdade para a informação tal qual a adotamos na Ciência da Informação? Como se produz a memória do futuro, questionando a produção de informação atual? Qual o limite entre ficção e realidade quando universos simbólicos estão envolvidos? Afirmase, de acordo com Žižek (2003, p. 34), que

[...] só temos condição de suportar o real se o transformamos em ficção. É necessário ter a capacidade de distinguir qual parte da realidade é 'transfuncionalizada' pela fantasia, de forma que, apesar de ser parte da realidade, seja percebida num modo ficcional.

Realidade e ficção misturam-se, assim, para construir a memória e suas variáveis de verdade.

No segundo, A Camareira do Titanic (no original La femme de chambre du Titanic), com produção de 1997 dirigida por Bigas Luna, o enredo é descrito buscando-se o diálogo entre imaginação (ficção) e realidade (A CAMAREIRA..., 1997). A informação, como elemento que transforma estruturas, está presente em toda a trama, ora a serviço da imaginação, ora da Realidade ainda que no patamar da ficção.

O filme arma sua trama narrativa a partir da viagem realizada por um operário de mineração no sul da França, Horty, para ver a partida do Titanic. Essa viagem foi o prêmio concedido pelo patrão ao vencedor de uma espécie de gincana da qual os operários anualmente participam e Horty foi o vencedor da prova.

Se em Benjamin (1994) tempo e espaço são as rotas para que o narrador encontre um público que escuta histórias, o prêmio recebido por Horty para ir à Southampton, Inglaterra, ver a saída do navio Titanic, coloca em sua bagagem de volta à França uma riqueza experiencial que transforma a comunidade de mineiros em suas relações tanto familiares quanto nas de trabalho.

Como o viajante que vem de longe tem muito a contar, Horty percebe o interesse dos colegas sobre sua experiência na viagem e passa a narrá-la em capítulos diários no bar onde todos os homens se encontravam após o trabalho. A 
expectativa de agradar aos companheiros faz com que o agora contador de histórias incorpore em sua memória detalhes sugeridos pela comunidade de operários, com ênfase nas relações afetivas e sexuais que teria tido com uma camareira do Titanic.

Os maridos voltam para casa e começam a repetir com suas mulheres o que Horty contou que realizou com a camareira. As noites são mais intensas no bar, as mulheres também querem ouvir as histórias que as têm feito mais felizes. O sucesso do narrador é tanto que um produtor teatral chega à cidade e convida Horty, o grande narrador, a viajar por toda França e Itália contando sua grande história de amor e a tragédia que afundou o navio. A narrativa oral/cíclica benjaminiana (BENJAMIN, 1994) é aquela na qual não existem estórias individuais, existem acordos narrativos que devem proporcionar um certo tipo de êxtase entre o narrador e os ouvintes, não importa a veracidade da informação.

Ao final, o narrador de memórias torna-se um ator consciente de que conta ao público uma história de amor inventada, portanto falsa. Não importa mais o laço verdadeiro com o passado que deu origem às lembranças mas, tão somente, o aprendizado de agradar a uma plateia.

No terceiro exemplo, toma-se por objeto de análise o filme Crônica de uma certa New York (no original Joe Gould's secret) dirigido por Stanley Tucci, 2000. Valoriza-se a crônica como objeto memo-informacional em suas várias formas: fílmica, literária e oral. O enredo destaca o fenômeno da história oral e as vozes dos indivíduos comuns em uma metrópole dos anos de 1940 (CRÔNICA..., 2000).

Centrada nos personagens cronistas Joseph Mitchell e Joe Gould, a narrativa fílmica é discutida com ênfase nos embates entre história e memória; entre verdade e mentira, entre realidade e ficção; entre sanidade e loucura. Depreende-se que a busca da memória registrada, como um rastro documental do submundo da cidade de New York não poderia chegar a um fim, já que as memórias encontram na oralidade seu melhor espaço.

Quanto à informação, o filme mostrou que a história dos excluídos ainda está por se fazer, que a invisibilidade ainda é contemporânea e que o debate entre a história oficial e a memória de indivíduos e grupos anônimos permanece como 
uma 'desinformação' que encontra reverberação nos filmes, nas vanguardas artísticas e em discussões e teorias do campo acadêmico.

\subsection{Mapa conceitual sobre os contextos em que atua a desinformação}

O mapa conceitual de Brisola e Doyle (2019) busca organizar algumas visões em torno do conceito de desinformação e se propõe a embasar a discussão sobre as possibilidades contemporâneas de resistência a esse fenômeno. Para as autoras, a competência crítica em informação, ou seja, a aprendizagem e o desenvolvimento contínuo de um relacionamento crítico com a informação, é uma pista, pela via educativa, para que se possa resistir à desinformação.

Os mapas desse gênero são construções lógicas que partem de uma ideia nuclear que se conecta com outras ideias periféricas por semelhanças e diferenças, gênero e espécies, o todo e suas partes, causas e consequências, processos e seus produtos de modo a que possamos ter uma noção de cenários possíveis ou contextos.

Essas construções lógicas podem ser encontradas em Dahlberg (1992) que apresenta um modelo conceitual para a organização do conhecimento e estudos terminológicos, denominado Teoria Analítica do Conceito (orientada para o referente), visando a comunicação entre indivíduos. O conceito, para a autora, é entendido como a soma total das predicações verdadeiras sobre o objeto, sintetizada como uma 'unidade de conhecimento' (Figura 2). O triângulo semântico de Dahlberg (1992) denominado de Modelo de Construção de Conceitos mostra que as relações conceituais são obtidas por comparação entre os atributos verdadeiros de determinado objeto. 
Figura 2 - Modelo de construção de conceitos
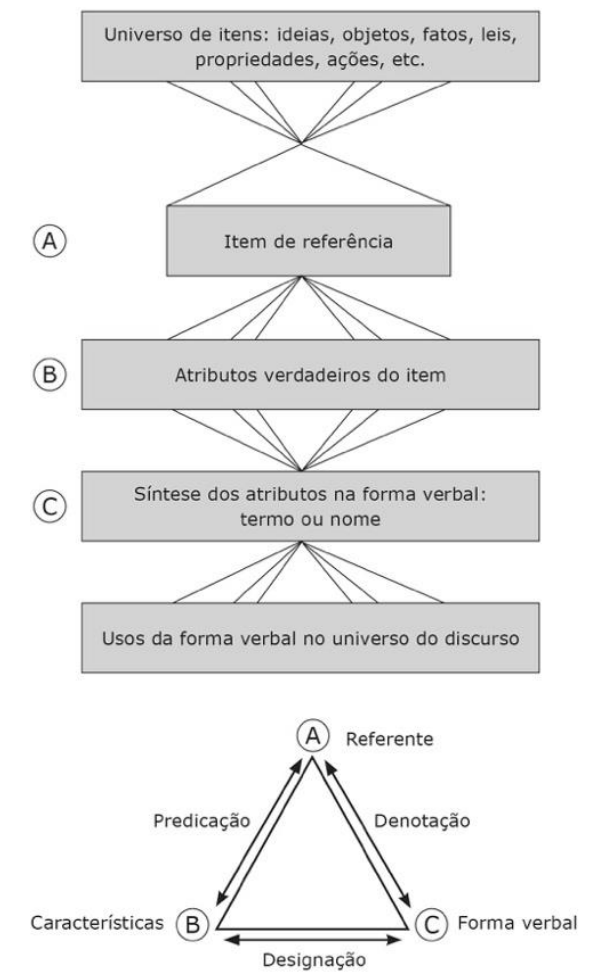

Fonte: Adaptado de Dahlberg (1992).

Conforme Logan (2012) propõe para o estudo da informação e Volkoff (1999) para o controle da desinformação a partir de provas e fontes confiáveis, o contexto é absolutamente necessário para creditar um discurso. Joe Gould, o cronista e guardião das memórias de New York, também precisava estabelecer contextos como os bares que frequentava, as festas de grupos de artistas e da elite, até a existência de uma Fundação Joe Gould contextualizada apenas em sua mente memorável.

Nesse sentido, os mapas conceituais a exemplo do mapa da desinformação (Figura 3), além de servirem à organização do conhecimento científico, à construção de linguagens documentárias, tesauros, ontologias, são instrumentos muito úteis à contextualização de processos de comunicação. 
Figura 3 - Mapa conceitual da desinformação

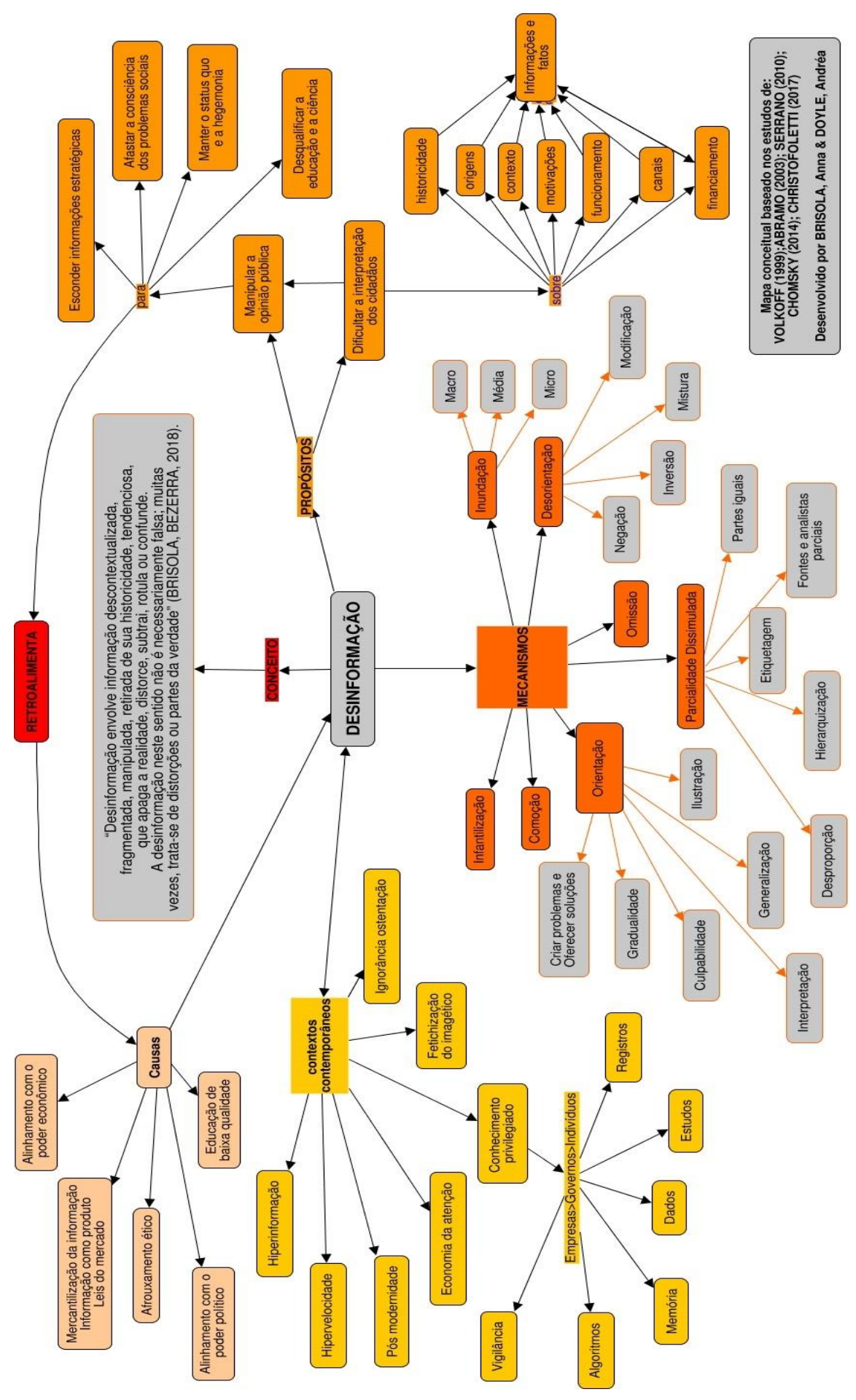

Fonte: Brisola e Doyle (2019, p. 280). 


\section{Considerações finais}

Procurou-se compreender os sentidos e significados dos conceitos de informação e desinformação a partir de dois autores: Robert Logan com a ideia de informação, e Vladimir Volkoff, com a história da desinformação, colocando-os em diálogo com Abbagnano e o Oxford Dictionaries no contexto da verdade e pós-verdade.

Como metodologia de análise foram utilizadas algumas narrativas fílmicas sobre Desinformação/Pós-verdade e Informação; Desinformação/Pós-verdade e Memória e Desinformação/Pós-verdade e História.

Ingetraut Dhalberg $(1992,1978)$ foi ao encontro da proposta de análise do objeto de estudo - desinformação e pós-verdade - ao indicar que, em função de seu conteúdo ou significado, as relações entre os conceitos se dão mediante comparações: lógicas, formais, abstratas ou semânticas. Essas relações aparecem no mapa conceitual sobre desinformação, construído por Anna Brisola e Andréa Doyle (2019), com destaque para quatro categorias principais apresentadas: causas, contextos contemporâneos, mecanismos e propósitos.

Como toda classificação é subjetiva e engajada, bem como são também as escolhas dos discursos autorais, diálogos e questionamentos em contextos discursivo-conceituais, foram apresentadas neste texto apenas possibilidades de compreensão de ações informacionais que ocorrem no mundo contemporâneo.

A questão - Fake News é informação? - abre caminho para próximas conversas.

\section{Financiamento}

Conselho Nacional de Desenvolvimento Científico e Tecnológico - CNPq; Coordenação de Aperfeiçoamento de Pessoal de Nível Superior - CAPES; Universidade Federal do Rio Grande do Sul - URGS/Programa de Pós Graduação em Ciência da Informação - PPGCI. 


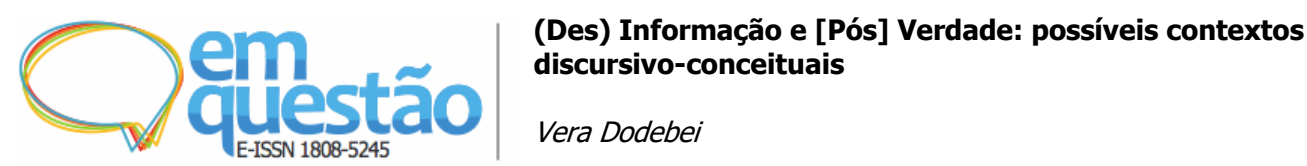

\section{Agradecimentos}

Às doutorandas do IBICT/UFRJ Anna Brisola e Andréa Doyle, por nossas conversas, troca de textos e, principalmente, pela cessão do mapa conceitual da desinformação.

\section{Referências}

ABBAGNANO, Nicola. Verdade. In: ABBAGNANO, Nicola. Dicionário de filosofia. São Paulo: Martins Fontes, 2000. p. 994-998.

A CAMAREIRA do Titanic. Direção: Bigas Luna. Itália: [s. n.], 1997. 1 fita de vídeo (99 min), VHS, son., color.

BENJAMIN, Walter. O narrador: considerações sobre a obra de Nikolai Leskov. In: BENJAMIN, Walter. Magia e técnica, arte e política: ensaios sobre a literatura e história da cultura. 7. ed. São Paulo: Brasiliense, 1994. v. 1. p. 197221.

BRISOLA, Anna; DOYLE, Andréa. Critical information literacy as a path to resist fake news: understanding disinformation as the root problem. Open

Information Science, [s. l.], v. 3, n. 1, p. 274-286, 2019. DOI:

https://doi.org/10.1515/opis-2019-0019. Disponível em:

https://www.degruyter.com/document/doi/10.1515/opis-2019-0019/html.

Acesso em: 16 fev. 2021.

CRÔNICA de uma certa New York. Direção: Stanley Tucci. Barueri: Europa Filmes, 2000. 1 DVD (107 min), son., color.

DAHLBERG, Ingetraut. Knowledge organization and terminology:

philosophical and liguistic bases. International Classification, Frankfurt, v. 19, n. 2, p. 65-71, 1992.

DAHLBERG, Ingetraut. Teoria do conceito. Ciência da Informação, Rio de Janeiro, v. 7, n. 2, p. 101-107, 1978.

DODEBEI, Vera. Ensaio sobre memória e informação. Revista Morpheus:

estudos interdisciplinares em memória social, Rio de Janeiro, v. 9, n. 15, p. 227 244, 2016.

HAN, Byung-Chul. No enxame: perspectivas do digital. Petrópolis, RJ: Vozes, 2018. 


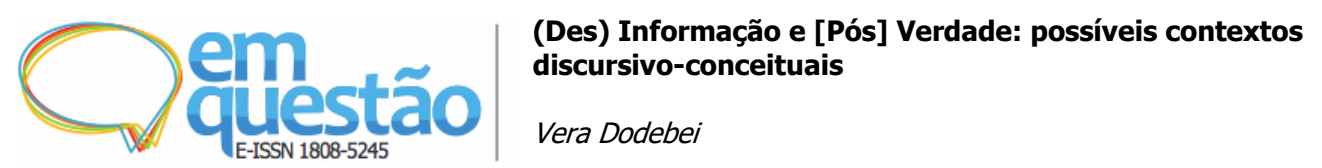

INTERVOZES. Desinformação: ameaça ao direito à comunicação muito além das fake-news. São Paulo: Intervozes, 2019. Disponível em:

https://intervozes.org.br/publicacoes/desinformacao-ameaca-ao-direito-acomunicacao-muito-alem-das-fake-news/. Acesso em: 16 fev. 2021.

KOPENAWA, Davi; ALBERT, Bruce. A queda do céu: palavras de um xamã yanomami. São Paulo: Companhia das Letras, 2015.

KRENAK, Ailton. No Rio para mediar ciclo de debates sobre o planeta, líder indígena critica 'lógica de produção' que gera crises como o derramamento de óleo nas praias do Nordeste. Entrevistador: William Helal Filho. O Globo, Rio de Janeiro, v. 95, n. 31.511, p. 28, 15 nov. 2019.

LOGAN, Robert K. Que é informação?: a propagação da organização na biosfera, na simbolosfera, na tecnosfera e na econosfera. Rio de Janeiro: Contraponto: PUC-Rio, 2012.

MERA Coincidência. Direção: Barry Levison. Burbank: New Line Cinema, 1997. 1 DVD (97 min), son., color.

OXFORD LANGUAGES. Palavra do ano 2016. [S .l.]: Oxford University Press, [2016]. Disponível em: https://languages.oup.com/word-of-theyear/2016/. Acesso em: 13 fev. 2021.

OXFORD LANGUAGES. Post-Truth frequency. [2019?]. 1 ilustração. Disponível em: https://languages.oup.com/word-of-the-year/2016/. Acesso em: 13 fev. 2021.

RÓNAI, Paulo. Dicionário universal Nova Fronteira de citações. Rio de Janeiro: Nova Fronteira, 1985.

SHANNON, Claude Elwood; WEAVER, Warren. Teoria matemática da comunicação. Rio de Janeiro: Difel, 1975.

VOLKOFF, Vladimir. Petite histoire de la désinformation: du cheval de Troie à Internet. Monaco: Édition du Rocher, 1999.

ŽIŽEK, Slavoj. Bem-vindos ao deserto do real! cinco ensaios sobre o 11 de setembro e datas relacionadas. São Paulo: Boitempo, 2003. 


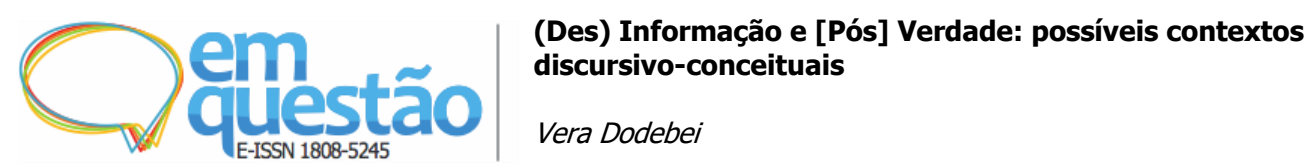

\title{
[Post] Truth and (Dis) Information possible discursive-conceptual contexts
}

\begin{abstract}
This article aims to discuss the ideas of disinformation and post-truth from their opposites - information and truth. In the light of Dahlberg's theory of concept, complemented by an analysis of three film narratives, possible conceptual scenarios were described with the support of an ultra-selective bibliographic search on each of the concepts. Robert Logan led the discussion on the concept of information and Nicola Abbagnano on the concept of truth. Vladimir Volkoff historiographed the concept of disinformation and the Oxford Dictionaries the post-truth. In conclusion, the true attributes or conceptual characteristics guaranteed by the literature allowed us to affirm the circumstantiality of the cultural contexts in which these concepts are organized, as well as allowing us to present two structures of analysis: a discursive and polysemic (filmic narratives) and a conceptual and semantic reducer (concept map) for the ideas of information and disinformation, truth and post-truth.
\end{abstract}

Keywords:. Disinformation. Information. Truth. Post-Truth. Theory of concept.

Recebido: 29/12/2019

Aceito: 09/08/2019

\section{Declaração de autoria}

Concepção e elaboração do estudo: Vera Dodebei

Coleta de dados: Vera Dodebei

Análise e discussão de dados: Vera Dodebei

Redação e revisão do manuscrito: Vera Dodebei

\section{Como citar}

DODEBEI, Vera. (Des) Informação e [Pós] Verdade possíveis contextos discursivo-conceituais. Em Questão, Porto Alegre, v. 27, n. 2, p. 117-137, abr./jun. 2021.

Doi: http://dx.doi.org/10.19132/1808-5245272.117-137

\footnotetext{
${ }^{1}$ LÉVI-STRAUSS, Claude. Présentation Chroniques d'une Conquête. Ethnies, [s. l.], n. 7, v. 14, p. 5-7, 1993. Apud Kopenawa e Albert (2015).
} 